\title{
Assessment of platelet function and resistance to aspirin and clopidogrel in patients with peripheral arterial disease undergoing percutaneous transluminal angioplasty
}

\author{
Grzegorz Borowski', Aleksandra Nowaczyńska² \\ 'Department of Vascular Surgery and Angiology, Medical University of Lublin, Lublin, Poland \\ ${ }^{2}$ Department of Hematooncology and Bone Marrow Transplantation, Medical University of Lublin, Lublin, Poland
}

\begin{abstract}
Introduction: Analysis of platelet function, acetylsalicylic acid (ASA) and clopidogrel resistance in patients with peripheral arterial disease (PAD) undergoing percutaneous transluminal angioplasty (PTA), the impact of procedure on this phenomenon, connection with diabetes, hypertension, smoking.

Material and methods: The study included 72 patients, with a group of patients taking ASA on a permanent basis and a group of patients in whom treatment was implemented after the procedure. Patients were also divided according to the antiplatelet therapy applied, either double-therapy, or ASA monotherapy. Daily doses were $75 \mathrm{mg}$. Three methods were used for the evaluation of the platelet function: MY bleeding time, cytometric evaluation of platelet surface antigen (CD62p and CD63) expression and hemostasis measurement by PFA-200 ${ }^{\circledR}$. Results: In the PFA-200 analysis, ASA resistance was found in 37.8\% (64.7\% were tobacco smokers) before surgery. Patients not taking ASA before, after PTA and first dose of ASA presented resistance in $63 \%$. The first dose of clopidogrel after surgery was associated with resistance in 73.7\%. Significant differences in the expression of CD62p and CD63 markers before and after PTA were observed. According to MY method, aspirin resistance was found in $40 \%$ of patients permanently receiving ASA.

Conclusions: Patients with PAD who undergo PTA are resistant to ASA in 40\%, smoking is associated with this phenomenon. PTA increases the expression of CD62P and CD63, and thus the platelet activation, which is not adequately prevented by antiplatelet drugs at a dose of $75 \mathrm{mg}$. Dual antiplatelet therapy reduces the activation of thrombocytes more than the monotherapy of ASA.
\end{abstract}

Key words: platelet function, aspirin resistance, clopidogrel resistance, peripheral artery disease, percutaneous transluminal angioplasty

Acta Angiol 2020; 26, 4: I19-128

\section{Introduction}

Endovascular treatment, due to its low invasiveness and good results, is commonly used in the treatment of patients with peripheral arterial disease (PAD), allowing to shorten hospitalization and recovery time. Percutaneous transluminal angioplasty (PTA), apart from the fact that it is associated with an increase in the activity of platelets, carries the risk of complications, including thrombosis. The prophylaxis of these complications currently includes antiplatelet drugs most often acetylsalicylic acid (ASA) and clopidogrel. ASA is the secondary prophylaxis after PTA and the primary antithrombotic prevention in patients diagnosed with 
symptomatic atherosclerosis of the lower extremities. Its use at a dose of $75-150 \mathrm{mg} /$ day in patients with intermittent claudication significantly reduces the rates of strokes, myocardial infarctions and deaths caused by cardiovascular diseases. This dose of ASA was found to be as effective as higher daily doses [I]. In randomized trials [2, 3], there was also no correlation between the amount of ASA used and the achievement of antiplatelet effect. The use of high doses appears to be unjustified and is related with a higher risk of gastrointestinal bleeding [4-6]. ASA also improves vessel patency after revascularization [7]. Dual antiplatelet therapy (ASA and clopidogrel) is implemented i.a. in patients who underwent stent implantation into peripheral arteries $[7,8]$. Despite the use of such therapy, adverse events, including stent thrombosis, are still observed [2, 7, 9 , 10]. In patients with PAD, there is a tendency to increased platelet activity, which may be resistant to the antiplatelet effect of ASA [ I I, 12]. The term aspirin resistance was first used in the early 1990s [13]. Aspirin resistance is defined either in terms of clinical symptoms (a thromboembolic event during drug use) or on the basis of laboratory tests determining the aggregating effect of platelets [14]. According to Patrono [15], the term aspirin resistance can be applied to clinical conditions or laboratory measurements, e.g. the inability of aspirin to: protect the patient from thromboembolic complications, prolong bleeding time, block thromboxane synthesis, or produce an antiplatelet effect found in one or more in vitro tests. Aspirin resistance is also defined by the term high on-treatment platelet reactivity (HTPR) [16] or high residual platelet reactivity (HRPR) during aspirin treatment [ I7]. In current reports, HRPR is recognized in $27.7 \%$ of respondents [17]. The concept of aspirin poor responsiveness (APR) is also used [18]. As for the laboratory determination of resistance, it is possible to assess the aggregation response of thrombocytes to arachidinate, adrenaline or collagen [14, 19, 20]. Another issue in antiplatelet therapy is resistance to clopidogrel, an antagonist of the P2YI 2 receptor. According to studies [2I], resistance to clopidogrel at a loading dose of $600 \mathrm{mg}$ was found in $I$ in 5 patients. However, in the reports from 2016 $[22,23]$ in the Chinese population of patients after ischemic stroke, taking clopidogrel at a dose of $75 \mathrm{mg} /$ /day, using the aggregometry method, drug resistance was found respectively in $38.88 \%$ and $36 \%$ of them (light transmission aggregometry — LTA). According to Spiliopoulos et al., the prevalence of resistance to aspirin and clopidogrel in patients undergoing endovascular interventions due to symptomatic PAD is approximately $50 \%$ [16]. The aim of this study was to assess the occurrence of resistance to antiplatelet drugs (acetylsalicylic acid and clopidogrel) in patients undergoing angioplasty, to determine the impact of the procedure on the development of aspirin resistance, to determine whether there is a relationship between the occurrence of drug resistance and diabetes, hypertension or smoking and the assessment of platelet activity based on the expression of platelet surface glycoproteins on the day after the procedure depending on the antiplatelet therapy used (monotherapy with ASA or ASA in combination with clopidogrel).

\section{Material and methods}

The study was conducted in the Department of Vascular Surgery and Angiology of the Medical University of Lublin from December 20 I I to December 20 I 5. Cytometric tests and analysis of thrombocyte function using the INNOVANCE PFA- $200^{\circledR}$ analyzer were performed in the Laboratory of Flow Cytometry and Hemostasis at the Department of Hematooncology and Bone Marrow Transplantation at the Medical University of Lublin. The study included a total of 72 patients (Table I) with PAD, aged 44 to 89 , including 20 women and 52 men. Each patient underwent PTA. The patients were qualified for angiography and endovascular treatment based on the clinical condition assessed on the basis of the Fontaine scale - grades IIB, III, IV.

After initial angiography, balloon angioplasty was performed in 34 (47.2\%) patients. One or more stents were implanted in 38 (52.8\%) patients. The endovascular procedure was performed on iliac arteries in 26 patients, in 46 patients on femoral, popliteal or tibio-fibular arteries (Table 2). During each procedure a bolus of unfractionated heparin i.v. (2500-5000 IU) was injected.

A group of 45 patients who were taking ASA at a dose of $75 \mathrm{mg}$ daily for at least 2 weeks before the planned surgery was selected. The remaining 27 patients had not received any antiplatelet medication for at least 7 days prior to PTA. After returning from the operating room, patients who underwent balloon angioplasty $(n=34)$ received $75 \mathrm{mg}$ of ASA, while those after stent implantation $(n=38)$ received $75 \mathrm{mg}$ of ASA and $75 \mathrm{mg}$ of clopidogrel (Table 3).

In studied patients, on the day of the procedure before its performance and on the first day after the procedure, the following additional tests were performed to assess platelet function: measurement of the occlusion time using the PFA-200 analyzer, cytometric analysis, bleeding time (BT) measured according to the Ivy method. The material for laboratory tests was fasting whole blood collected from the cephalic vein using a 20Gx Needle (Sarstedt S-Monovette Nümbrecht, Germany). Blood was collected in 3 polystyrene tubes (Sarstedt S-Monovette) containing 3.2\% sodium 
Table I. Clinical characteristics of the study population $(n=72)$

\begin{tabular}{|c|c|c|}
\hline The assessed parameter & Number of patients in the entire study group & Percentage of patients in the entire study group \\
\hline \multicolumn{3}{|l|}{ Gender } \\
\hline Male & 52 & $72.2 \%$ \\
\hline Female & 20 & $27.8 \%$ \\
\hline \multicolumn{3}{|l|}{ Diabetes } \\
\hline Yes & 23 & $39.1 \%$ \\
\hline No & 49 & $68.1 \%$ \\
\hline \multicolumn{3}{|l|}{ Arterial hypertension } \\
\hline Yes & 38 & $52.8 \%$ \\
\hline No & 34 & $47.2 \%$ \\
\hline \multicolumn{3}{|l|}{ Nicotinism } \\
\hline Yes & 30 & $41.7 \%$ \\
\hline No & 42 & $58.3 \%$ \\
\hline
\end{tabular}

Table 2. Characteristics of the performed endovascular procedures

\begin{tabular}{|l|c|}
\hline Number of patients who underwent balloon angioplasty & $34(47.2 \%)$ \\
\hline Number of patients with stent implantation & $38(52.8 \%)$ \\
\hline Number of procedures performed within iliac arteries & $26(36.1 \%)$ \\
\hline Number of procedures performed within femoral, popliteal arteries and tibial-peroneal trunk & $46(63.9 \%)$ \\
\hline
\end{tabular}

Table 3. Pharmacological treatment in the perioperative period

\begin{tabular}{|l|c|c|c|}
\hline \multicolumn{2}{|l}{$\begin{array}{c}\text { Antiplatelet drugs administered } \\
\text { permanently before the procedure }\end{array}$} & Number of & Antiplatelet drugs administrated at the day \\
of the procedure, after its performance & $\begin{array}{c}\text { Number of } \\
\text { patients }\end{array}$ \\
\hline ASA & 45 & ASA & 34 \\
\hline Clopidogrel & 0 & ASA + clopidogrel & 38 \\
\hline Without antiplatelet drug & 27 & Without antiplatelet drug & 0 \\
\hline
\end{tabular}

citrate in the proportion 1:9. Then, within 2 hours of collection, the occlusion time was analyzed using the PFA-200 and the expression of platelet glycoproteins with the use of a cytometric analyzer.

\section{Description of the methods of assessing platelet function used in the study}

The PFA $-200^{\circledast}$ system is used to measure the primary hemostasis process. It allows for a quick assessment of platelet function based on the analysis of non-clotted whole blood collected in citrate. With its use, it is possible to diagnose congenital and acquired platelet defects, as well as to evaluate drug-induced dysfunctions. Using the flow cytometry method, the activation of platelets and their function can be tested. For this purpose, monoclonal antibodies that are directed against platelet surface antigens are used. Specific phenotypic changes in platelet glycoproteins can be determined by the use of fluorescent-labeled antibodies. Changes in the expression of CD62p (P-selectin) and CD63 (GP53 glycoprotein) surface proteins were found in numerous studies. These two molecules are the most expressive markers of platelet activation [24, 25]. In our study, the measurement of bleeding time (BT) using the lvy method was also used. It is the only way to assess hemostasis in vivo. The bleeding time is the time between the incision is made and bleeding stops [26]. It proves the ability of platelets to form a blood clot at the site of skin damage. Standardized Surgicutt ${ }^{\circledR}$ Adult skin incision lancet were used to measure bleeding time. The correct bleeding time for the lvy method was assumed to be 6 minutes [26-29]. The group of patients with bleeding time up to 360 seconds was defined as resistant to the antiplatelet effect of used drugs. 


\section{Statistical methods}

Statistical analyzes were performed using the Statistica 9. The following methods were used: descriptive statistics (mean, median, minimum, maximum, standard deviation, standard error of the mean); percentage analysis; tests of significance of differences - Mann-Whitney $\mathrm{U}$ test, sign test for dependent groups, Kruskal-Wallis test, $\mathrm{Chi}^{2}$ test; correlation analysis using the r-Pearson coefficient. The critical level of statistical significance was $p<0.05$.

\section{Results}

\section{Resistance to the antiplatelet effect of aspirin measured with PFA-200}

The mean closure time (CT) measured with the Col/ /EPI test cartridges in the group of 45 patients receiving ASA on a permanent basis before surgery was 185.6 seconds. After the procedure, the CT was shortened to an average of $170.5 \mathrm{~s}$. This means that PTA, despite the daily use of ASA, is associated with a decreased response to the antiplatelet effect of the drug. In the group of 45 patients taking ASA, drug resistance was found in $37.8 \%$ of patients using the PFA-200 device $(n=17)$. In the same group of patients, after PTA, a reduced response to the effects of ASA was observed in a greater number of patients $46.7 \%(n=21)$. In the studied group of ASA-resistant patients $(n=17)$, a high percentage of smokers $(64.7 \%)$ and a low percentage of diabetics $(35.3 \%)$ were found. The coexistence of arterial hypertension is not associated with the aspirin resistance $(53 \%$ in the study group are diagnosed with this disease). In the group of 27 patients not taking the drug before the procedure, CT was measured on the first day of the procedure and aspirin resistance was found in $63 \%$ of them $(n=17)$. ASA at a dose of $75 \mathrm{mg}$ administrated only after PTA is associated with a very high percentage of resistance. In the entire group of 72 patients participating in the study, a reduced response to the effects of ASA, measured with the PFA-200, was found in 38 patients $(52.8 \%)$. Therefore, regardless of whether the patients were taking ASA in the period before the procedure or they received the drug only after the procedure, an increase in resistance caused by PTA was found. When analyzing the whole study population, a low percentage of diabetic patients was found in the drug-resistant group $(n=38)$. However, the coexistence of arterial hypertension and smoking was not related with the occurrence of this phenomenon.

\section{Resistance to the antiplatelet effect} of clopidogrel measured with PFA-200

In a group of 38 patients in whom at least one stent was implanted, after administration of a dose of $75 \mathrm{mg}$ clopidogrel immediately after surgery, a study was performed with P2Y test cartridges. The patients had not taken the drug before. The drug resistance was found in 28 subjects (73.7\%). This means that clopidogrel is less effective at this dose on the first day of its use. In the group of patients resistant to the first dose of $75 \mathrm{mg}$ clopidogrel after stenting $(n=28)$, a higher percentage of smokers $(60.7 \%)$ compared to non-smokers was observed. Patients with diabetes accounted for only $28.6 \%$ of the group. The number of patients with hypertension was the same as the number without. In the group of patients responding to clopidogrel $(n=10)$, a very low percentage of patients with diabetes (20\%) was found.

\section{Expression of P-selectin}

In the group of patient taking ASA $(n=45)$ before PTA, the mean percentage of platelet activation measured with CD61/CD62P was 0.36 , after the procedure, it was increased to $0.5 \mathrm{I}$. In the group of patients who did not take the drug before PTA $(n=27)$, the mean percent activation for CD61/CD62P cells was 0.25 and after surgery it increased to 0.74 . The mean percentage of $\mathrm{CD} 6 \mathrm{I} / \mathrm{CD} 62 \mathrm{P}$ cell activation in patients after surgery (PTA with stent implantation) and dual antiplatelet therapy $(n=38)$ was 0.79 . Before the procedure, this value was lower, averaging 0.33 . Similarly, in patients after PTA without stent implantation and using a single antiplatelet therapy with ASA $(n=34)$ before procedure, the value was lower than after (0.5) and was 0.37. In the entire group of patients with PAD $(n=72)$, the mean value of the parameter before the procedure was 0.32 . The surgery, despite the used antiplatelet therapy, increased the activation of platelets to the mean value of 0.60 .

\section{Expression of CD63}

Both in treated with ASA $(n=45)$ and ASA-free group $(n=27)$, the mean percentage of postoperative CD6I/ /CD63 cell activity was higher than before (2.0 and 1.17 and 1.39 and I.15). This means an increase in the expression of the platelet activation marker (CD63) as a result of the PTA, despite the use of antiplatelet therapy after the procedure (in this case, regardless of whether the patients received ASA or ASA and clopidogrel). Mean percentage of CD6I/CD63 cell activity in postoperative period (PTA with stent implantation) and dual antiplatelet therapy $(n=38)$, as in patients (with PTA without stent implantation) and with ASA monotherapy $(n=34)$ as in the entire group of 72 patients before the procedure was lower (1.57; I.76; I.50, respectively) compared to post-procedural testing (2.05; I.95; I.80, respectively). The surgery, despite the antiplatelet therapy used, increases the activation 
of platelets, measured with the use of CD6I/CD63 antibodies.

\section{Results of tests with assessment of bleeding time using the Ivy method}

The mean bleeding time (BT) measured using the lvy method for the group permanently receiving ASA before surgery $(n=45)$ was 444 seconds. In the group of patients taking ASA at a dose of $75 \mathrm{mg}$ a day $(\mathrm{n}=$ $=45$ ), the bleeding time was normal in 18 patients, so in $40 \%$ of patients, the drug did not prolong bleeding time, and thus this group can be considered as with low sensitivity to the antiplatelet effect of ASA. In the group of patients who underwent stenting and receiving dual antiplatelet therapy $(n=38)$, on the first day of PTA, the bleeding time was normal in I 3 patients (34.2\%). In the group of patients who were treated with ASA $75 \mathrm{mg}$ monotherapy $(n=34)$, the correct bleeding time was detected in 14 patients, which means $41.2 \%$ of drug resistance. The mean bleeding time was 408 seconds, which was shorter than in the dual antiplatelet therapy group (477.2 seconds). The use of dual antiplatelet therapy results in a better antiplatelet effect as it increases bleeding time. In the group of ASA-resistant patients tested before the PTA procedure $(n=17)$, the correct bleeding time was also found before the procedure in 5 of them, which is $29.4 \%$. In the assessment before the angioplasty procedure, in the group of 45 patients receiving ASA permanently, there were 5 patients resistant to the drug effect according to the two methods used in the study, which constitutes $11.1 \%$.

\section{Discussion}

Numerous studies report that the resistance to the antiplatelet effect of acetylsalicylic acid may affect from 5 to $60 \%$ of patients, this discrepancy depending on the studied population and methods used to evaluate it. According to some researchers, this percentage is even as high as $83 \%$ [ $1,30-34]$. One of the first published reports on ASA resistance concerned its use in secondary prevention in patients with stroke - the above problem was found (using PFA-100) in $30-40 \%$ of patients [35]. In our study, with the use of the PFA-200 device, in a group of patients with PAD who took ASA on a permanent basis, drug resistance was found in a very similar percentage of patients - $37.8 \%$. In the study of Linneman et al. [36], the change in response to the effect of ASA was tested over time in patients with PAD, using e.g. PFA analyzer. It has been found that in a significant number of patients, resistance to aspirin changes over time during treatment. It may be related to inconsistency in the methodology, incompatibility in the applied therapy, insufficient response to the selected dose of the drug or interactions with other drugs. In addition, platelet activity may change as the disease progresses. In this study, resistance to aspirin and platelet function were assessed only before the PTA procedure and in the first 24 hours after. This resulted from the planned evaluation of the drug resistance in the periprocedural period, the aim of which was to determine the impact of the procedure itself on the resistance and to assess the effectiveness of the doses of drugs used at that time. For this reason, the possible long-term dynamics of the response to antiplatelet drugs was not assessed. There were also observations that resistance to ASA progressed over time, regardless of the dose taken [37, 38]. In a study [39] where platelet function was measured several times over 12 months of ASA use, response to the drug did not matter in determining long-term outcomes. In a meta-analysis assessing the effect of aspirin in prevention of thromboembolic complications, it was found that most of the studies performed used different methods of testing the laboratory activity of thrombocytes. Furthermore, despite the same methods, different cut-off points were used. It has been found that patients presenting aspirin resistance in biochemical tests also tend to be "clinically resistant" with a significantly higher risk of cardiovascular complications. People with a significant activation of platelets, despite the use of aspirin, show an almost four times higher total risk of a cardiovascular event [40].

In our research, it was observed that in the group of patients identified as aspirin-resistant before PTA $(n=17), 64 \%$ were tobacco smokers. However, in the group of aspirin-resistant patients $(n=38)$ selected from the entire study population $(n=72)$, nicotinism coexisted in $55 \%$ of them. This confirms previous researches that smoking tobacco can cause drug resistance. It can be concluded that the increased pro-aggregation activity of thrombocytes in smokers, as in other studies [4I, 42], is the main factor determining the higher incidence of cardiovascular diseases despite the systematic use of the drug in prophylactic doses. In this study, both in the group of patients diagnosed as aspirin-resistant before the procedure $(n=17)$ and in the entire study group on the day after the procedure $(n=38)$, the percentage of patients with coexisting diabetes was nearly $40 \%$, which does not coincide with the majority of previous studies, suggesting that a patient with diabetes is more often drug-insensitive. In diabetic patients, increased activity with a tendency to aggregation of platelets was found, and therefore a higher incidence of thromboembolic complications $[43,44]$. However, according to some reports, diabetes does not affect the development of aspirin resistance and the percentage of this phenomenon among dia- 
betics is comparable to the group of patients without diagnosed diabetes $[45,46]$. The clinical importance of biochemically determined aspirin resistance in the development of cardiovascular complications has been confirmed [13,35]. For example, in the study of Gum et al. [33], it was suggested that about $10 \%$ of recurrent adverse vascular events may be caused by resistance to ASA. This confirms that such prognosis of clinical complications, correlating with laboratory resistance, is extremely important for defining the scope and nature of resistance to antiplatelet drugs. Several studies have shown that patients with a decreased response to clopidogrel, measured in vitro using platelet function analyzers have a significantly increased risk of early stent thrombosis after percutaneous coronary angioplasty (PTCA) compared to patients with sufficient platelet function blocking [23]. Most of the studies on clopidogrel resistance concerned the study of platelet function after a loading dose of $300 \mathrm{mg}$ [47]. In our study, the antiplatelet effect of clopidogrel was tested with the first day of $75 \mathrm{mg}$ dose. Such a study was designed to determine whether the applied dose is effective in this group of patients, or whether it is worth considering using a higher dose on the day of surgery. Resistance to clopidogrel also varied between investigators, but there was a correlation between laboratory resistance and cardiovascular adverse events. In the work of Metzky et al. [48], patients with myocardial infarction treated with angioplasty were monitored for the effect of clopidogrel by the optical aggregation method, using ADP as an agonist. This allowed identification of a group of $25 \%$ of patients resistant to the drug effect, and thus more at risk of recurrent cardiovascular events. The only characteristic of this group was the high percentage of tobacco smokers. In the study by Cuisset et al. on patients with acute coronary syndrome, there was described a higher frequency of periprocedural infarctions in the group with a poor laboratory response to clopidogrel $[49,50]$. So far, a small number of studies have been published assessing the antiplatelet efficacy of clopidogrel tested with the PFA-200 analyzer [5I]. In our study, the tests were made on the first day of the procedure, so the assessment concerns one dose of $75 \mathrm{mg}$, confirming its very low effectiveness. Only 10 patients had a correct response to the drug, which is $26.3 \%$ in the study group. The remaining patients (73.7\%) can be diagnosed with reduced responsiveness to the antiplatelet effect of clopidogrel. In this study, the cytometric test and the lvy method for the bleeding time were used to compare dual antiplatelet therapy with ASA monotherapy. P-selectin and CD63 are established markers of thrombocyte activity measured by flow cytometry $[52,53]$. According to E. McKenzie et al. [53], a significant decrease in the expression of these glycoproteins was described only after a high dose of ASA, which suggests the use of higher doses in patients treated endovascularly. The expression of P-selectin and GP53 was examined in all patients included in the study $(n=72)$ both before and after surgery. It was found that P-selecting expression was higher in patients who underwent stenting and received two antiplatelet drugs compared to those who had only balloon angioplasty and received ASA.

As for CD63 expression, its level after PTA was comparable in both groups, regardless of the therapy used. Thus, stenting causes a greater activation of platelets, assessed by this marker, than balloon angioplasty itself. The inhibitory effect of ASA and clopidogrel on the expression of these markers of platelet activity (mainly P-selectin) described so far is weaker than the effect of endovascular treatment causing the increase in expression. The assessment of the bleeding time using the Ivy method was found to be normal in I 3 patients in the group that received dual antiplatelet therapy after stent implantation $(n=38)$. This means that $34.2 \%$ of the study group was not responsive to the effects of these drugs. On the other hand, in the group of patients after balloon angioplasty and receiving $75 \mathrm{mg}$ of acetylsalicylic acid ( $n=34), 41.2 \%$ were resistant after the procedure. Moreover, the mean bleeding time is also higher in patients treated with ASA and clopidogrel (477 vs 408 seconds). The above results, despite the lack of statistical significance, allow us to observe that dual antiplatelet therapy is associated with better inhibition of thrombocyte function resulting in prolonged bleeding time. It is worth paying attention to the fact that the implementation of such therapy is more effective even in relation to patients who have had a stent implanted, which is also associated with a higher activation of platelets than after balloon angioplasty only.

In this study, an increase in P-selectin expression after surgery, and thus in platelet activation, was found, assessed on a group of patients receiving ASA permanently $(n=45)$. In the preoperative ASA group ( $n=$ $=27$ ), a significant increase in the mean percentage of activation of CD6I/62p antibodies was observed. This difference is greater than in patients using ASA before the procedure, so it can be concluded that the treating patient with aspirin before the procedure results in a lower activation of platelets, and thus a lower risk of developing thrombotic complications in the first days after PTA. Some studies do not describe that aspirin impacts the level of P-selectin expression [54]. According to studies [53] with the use of flow cytometry, in which several markers of platelet activation were used, a decrease in P-selectin expression was found already at the dose of $1.0 \mathrm{~g}$ of ASA. On the other hand, after a higher dose of $4.0 \mathrm{~g}$, a statistically significant decrease 
in the expression of CD63 antibodies, while after a small dose, a slight increase in the expression of CD63. After a week of using ASA at a dose of $81 \mathrm{mg} /$ day, Valdes et al. [55] found a decrease in the concentration of soluble P-selectin (sP-selectin) in the blood. The studies carried out on a group of healthy people who were administered ASA in a dose of $8 \mathrm{I} \mathrm{mg} \mathrm{showed} \mathrm{that}$ there was a decrease in the expression of thrombocyte surface receptors, including P-selectin [56]. In this study, it was shown that the percentage of antibody activation before PTA was lower than after PTA, which means that in patients with PAD, angioplasty causes an increased activation of platelets, which is insufficiently prevented by the drugs used. The search for an effective antiplatelet therapy for patients with PAD is extremely important, also because these patients clearly have an increased risk of myocardial infarction or ischemic stroke [II]. In this study, in the group of patients permanently receiving ASA in a daily dose of $75 \mathrm{mg}$ $(n=45)$, the level of aspirin resistance confirmed by two methods - PFA-200 and the Ivy method was found in 5 patients, which makes $11 \%$ of this group. The above group of patients can be described as "true" aspirin-resistant, because they present the features of resistance in both biochemical and in the in vivo test. Moreover, studies evaluating aspirin resistance in relation to the development of thromboembolic complications in patients undergoing antiplatelet therapy estimate the prevalence of resistance at a very similar level. In the analysis of Gum et al. [33], the importance of aspirin resistance in thrombotic complications was estimated at $10 \%$. Similar results were presented by Saunders et al. [57], where in a group of 80 patients with PAD using the PFA-100, persistent aspirin resistance was detected in $9.9 \%$ of patients.

Despite many recent studies, it has not been possible to clearly define which group of patients should be diagnosed for aspirin resistance. Though the number of available, relatively simple and quick tests for determining the activity of platelets is increasing, the cost of the equipment and the tests themselves will not allow such extensive diagnostics in the near future. A definition of a patient resistant to aspirin and clopidogrel should be created, which will also enable the development of new or specification of already used tests independent of additional factors modifying the action of these drugs.

\section{Conclusions}

Based on the own research presented above, it was found that among patients with peripheral arterial disease treated with endovascular methods, the level of laboratory aspirin resistance is about $40 \%$. An addi- tional factor that increases the resistance to antiplatelet drugs is tobacco smoking. Previous PTA procedure results in increased resistance to antiplatelet drugs. As a result of PTA, the expression of P-selectin and CD63 increases, and thus the activation of platelets also increases, which is insufficiently prevented by the antiplatelet drugs used in the periprocedural period: ASA and clopidogrel. Dual antiplatelet therapy reduces the activation of platelets to a greater extent compared to acetylsalicylic acid monotherapy.

\section{Conflict of interest}

None.

\section{References:}

I. Baigent C, Blackwell L, Collins R, et al. Aspirin in the primary and secondary prevention of vascular disease: collaborative meta-analysis of individual participant data from randomised trials. The Lancet. 2009; 373(9678): 1849-1860, doi: 10.1016/ s0I40-6736(09)60503-I.

2. Antithrombotic Trialists' Collaboration. Collaborative meta-analysis of randomised trials of antiplatelet therapy for prevention of death, myocardial infarction, and stroke in high risk patients. BMJ. 2002; 324(7329): 7I-86, doi: 10.1 |36/bmj.324.7329.7I, indexed in Pubmed: I 178645 I.

3. van Gijn J, Algra A, Kappelle J, et al. Dutch TIA Trial Study Group. A comparison of two doses of aspirin ( $30 \mathrm{mg}$ vs. $283 \mathrm{mg}$ a day) in patients after a transient ischemic attack or minor ischemic stroke. N Engl J Med. 199|; 325(I8): |26|-1266, doi: 10.1056/ NEJMI99II03I325I80I, indexed in Pubmed: 1922220.

4. Derry S, Loke YK. Risk of gastrointestinal haemorrhage with long term use of aspirin: meta-analysis. BMJ. 2000; 321 (7270): II83-I 187, doi: 10.1136/bmj.321.7270.1183, indexed in Pubmed: 11073508.

5. Zimmermann N, Wenk A, Kim U, et al. Functional and biochemical evaluation of platelet aspirin resistance after coronary artery bypass surgery. Circulation. 2003; 108(5): 542-547, doi: 10.116I/0I.CIR.0000081770.51929.5A, indexed in Pubmed: I2874I88.

6. Bem D, Dretzke J, Stevens S, et al. Investigating the effectiveness of different aspirin dosing regimens and the timing of aspirin intake in primary and secondary prevention of cardiovascular disease: protocol for a systematic review. Syst Rev. 2015; 4: 88, doi: 10.1 I86/s |3643-015-0078-3, indexed in Pubmed: 26088608.

7. Tendera M, Aboyans V, Bartelink ML, et al. European Stroke Organisation, ESC Committee for Practice Guidelines. ESC Guidelines on the diagnosis and treatment of peripheral artery diseases: Document covering atherosclerotic disease of extracranial carotid and vertebral, mesenteric, renal, upper and lower extremity arteries: the Task Force on the Diagnosis and Treatment of Peripheral Artery Diseases of the European Society of Cardiology (ESC). Eur Heart J. 20I I; 32(22): 285I-2906, doi: 10.1093/eurheartj/ehr2II, indexed in Pubmed: 21873417.

8. Perk J, De Backer G, Gohlke H, et al. European Association for Cardiovascular Prevention \& Rehabilitation (EACPR), ESC Committee for Practice Guidelines (CPG). European Guidelines 
on cardiovascular disease prevention in clinical practice (version 2012). The Fifth Joint Task Force of the European Society of Cardiology and Other Societies on Cardiovascular Disease Prevention in Clinical Practice (constituted by representatives of nine societies and by invited experts). Eur Heart J. 2012; 33(13): |635-170I, doi: 10.1093/eurheartj/ehs092, indexed in Pubmed: 22555213.

9. Mazur P, Frołow M, Niżankowski R, et al. Impaired responsiveness to clopidogrel and aspirin in patients with recurrent stent thrombosis following percutaneous intervention for peripheral artery disease. Platelets. 2013; 24(2): 15I-155, doi: 10.3109/09537104.2012.676220, indexed in Pubmed: 22497730.

10. Linnemann B, Thalhammer A, Wolf Z, et al. Late peripheral stent thrombosis due to stent fracture, vigorous exercise and hyporesponsiveness to clopidogrel. Vasa. 20I2; 4 I (2): 136-144, doi: 10.1024/030I-1526/a000 I77, indexed in Pubmed: 22403। 33.

II. Matsagas MI, Geroulakos G, Mikhailidis DP. The role of platelets in peripheral arterial disease: therapeutic implications. Ann Vasc Surg. 2002; 16(2): 246-258, doi: 10.1007/s10016-001-0159-8, indexed in Pubmed: I 1972262.

12. Hiatt WR. Preventing atherothrombotic events in peripheral arterial disease: the use of antiplatelet therapy. J Intern Med. 2002; 25I(3): 193-206, doi: 10.1046/j.1365-2796.2002.00947.x, indexed in Pubmed: 11886478.

13. Grotemeyer KH. Effects of acetylsalicylic acid in stroke patients evidence of nonresponders in a subpopulation of treated patients. Thrombosis Research. 1991; 63(6): 587-593, doi: 10.1016/0049-3848(91)90085-b.

14. Doroszko A, Podgórska K, Drożdż K, et al. Resistance to acetylsalicylic acid — pathophysiology and clinical implications. Acta Angiologica. 2008; 14(3): 79-87.

15. Patrono C. Aspirin resistance: definition, mechanisms and clinical read-outs. J Thromb Haemost. 2003; I(8): 1710-1713, doi: 10.1046/j.1538-7836.2003.00284.x, indexed in Pubmed: |29|1581.

16. Spiliopoulos S, Kassimis G, Hatzidakis A, et al. High on-treatment platelet reactivity in peripheral endovascular procedures. Cardiovasc Intervent Radiol. 2014; 37(3): 559-571, doi: 10.1007/s00270-013-0707-y, indexed in Pubmed: 238975 II.

17. Oh MiS, Yu KH, Lee JH, et al. Aspirin resistance is associated with increased stroke severity and infarct volume. Neurology. 2016; 86(19): 1808-1817, doi: 10.1212/WNL.0000000000002657, indexed in Pubmed: 27060166.

18. Mrdovic I, Čolić M, Savic L, et al. Clinical Significance of Laboratory-determined Aspirin Poor Responsiveness After Primary Percutaneous Coronary Intervention. Cardiovasc Drugs Ther. 2016; 30(2): I5I-I58, doi: 10.1007/s 10557-016-6643-8, indexed in Pubmed: 26843365.

19. Michelson AD, Cattaneo M, Eikelboom JW, et al. Platelet Physiology Subcommittee of the Scientific and Standardization Committee of the International Society on Thrombosis and Haemostasis, Working Group on Aspirin Resistance. Aspirin resistance: position paper of the Working Group on Aspirin Resistance. J Thromb Haemost. 2005; 3(6): |309-13 | , doi: I0.1 | | |/j. I5387836.2005.01351.x, indexed in Pubmed: 15892858.

20. Cattaneo M. Aspirin and clopidogrel: efficacy, safety, and the issue of drug resistance. Arterioscler Thromb Vasc Biol. 2004;
24(II): 1980-|987, doi: |0.1 |6|/0|.ATV.0000|45980.39477.a9, indexed in Pubmed: 15388526.

21. Snoep JD, Hovens MMC, Eikenboom JC], et al. Clopidogrel nonresponsiveness in patients undergoing percutaneous coronary intervention with stenting: a systematic review and meta-analysis. Am Heart J. 2007; 154(2): 221-231, doi: 10.1016/j. ahj.2007.04.014, indexed in Pubmed: 17643570.

22. Yi X, Lin J, Zhou Q, et al. Clopidogrel Resistance Increases Rate of Recurrent Stroke and Other Vascular Events in Chinese Population. J Stroke Cerebrovasc Dis. 2016; 25(5): 1222-1228, doi: 10.1016/j.jstrokecerebrovasdis.2016.02.013, indexed in Pubmed: 26935 II 4.

23. Liu R, Zhou ZY, Chen YB, et al. Associations of CYP3A4, NRII2, CYP2CI 9 and P2RYI 2 polymorphisms with clopidogrel resistance in Chinese patients with ischemic stroke. Acta Pharmacol Sin. 2016; 37(7): 882-888, doi: 10.1038/aps.2016.41, indexed in Pubmed: 27133299.

24. van Velzen JF, Laros-van Gorkom BAP, Pop GAM, et al. Multicolor flow cytometry for evaluation of platelet surface antigens and activation markers. Thromb Res. 2012; 130(I): 92-98, doi: 10.1016/j.thromres.2012.02.04I, indexed in Pubmed: 22424855 .

25. Rubak P, Nissen PH, Kristensen SD, et al. Investigation of platelet function and platelet disorders using flow cytometry. Platelets. 2016; 27(I): 66-74, doi: 10.3109/09537104.2015.1032919, indexed in Pubmed: 25901600.

26. Chakroun T, Addad F, Abderazek F, et al. Screening for aspirin resistance in stable coronary artery patients by three different tests. Thromb Res. 2007; 121 (3): 413-418, doi: 10.1016/j. thromres.2007.04.010, indexed in Pubmed: 17553552.

27. Ochei J. Medical laboratory science: theory and practice. $2^{\text {nd }}$ edition ed. Tata McGraw-Hill Education, New Delhi 2000.

28. Schilling McCann JA. Nursing: deciphering diagnostic tests. Lippincott Williams \& Wilkins, Philadelphia 2007.

29. Brunner LS. Brunner \& Suddarth's handbook of laboratory and diagnostic tests. Wolters Kluwer/Lippincott Williams \& Wilkins, Philadelphia 2010.

30. Lev El, Patel RT, Maresh KJ, et al. Aspirin and clopidogrel drug response in patients undergoing percutaneous coronary intervention: the role of dual drug resistance. J Am Coll Cardiol. 2006; 47(I): 27-33, doi: 10.1016/j.jacc.2005.08.058, indexed in Pubmed: 16386660 .

31. Feher G, Feher A, Pusch G, et al. Clinical importance of aspirin and clopidogrel resistance. World J Cardiol. 2010; 2(7): I7I-186, doi: 10.4330/wjc.v2.i7. 171, indexed in Pubmed: 21160749.

32. Gurbel PA, Becker RC, Mann KG, et al. Platelet function monitoring in patients with coronary artery disease. J Am Coll Cardiol. 2007; 50(19): 1822-1834, doi: 10.1016/j.jacc.2007.07.05।, indexed in Pubmed: 17980247.

33. Gum P, Kottke-Marchant K, Poggio E, et al. Profile and prevalence of aspirin resistance in patients with cardiovascular disease. The American Journal of Cardiology. 200I; 88(3): 230-235, doi: 10.1016/s0002-9149(01)01631-9.

34. Shantsila E, Watson T, Lip* G. Aspirin resistance: What, why and when? Thrombosis Research. 2007; I 19(5): 55I-554, doi: 10.1016/j.thromres.2006.08.009.

35. Grundmann K, Jaschonek K, Kleine B, et al. Aspirin non-responder status in patients with recurrent cerebral ischemic 
attacks. J Neurol. 2003; 250(I): 63-66, doi: 10.1007/s004I5003-0954-y, indexed in Pubmed: 12527994.

36. Linnemann B, Prochnow S, Mani H, et al. Variability of non-response to aspirin in patients with peripheral arterial occlusive disease during long-term follow-up. Ann Hematol. 2009; 88(I0): 979-988, doi: 10.1007/s00277-009-0708-8, indexed in Pubmed: 19247655.

37. Pulcinelli FM, Pignatelli P, Celestini A, et al. Inhibition of platelet aggregation by aspirin progressively decreases in long-term treated patients. J Am Coll Cardiol. 2004; 43(6): 979-984, doi: 10.1016/j.jacc.2003.08.062, indexed in Pubmed: 15028353.

38. Maree AO, Curtin RJ, Dooley M, et al. Platelet response to low-dose enteric-coated aspirin in patients with stable cardiovascular disease. J Am Coll Cardiol. 2005; 46(7): 1258-1263, doi: 10.1016/j.jacc.2005.06.058, indexed in Pubmed: 16198840.

39. van der Loo B, Braun J, Koppensteiner R. On-treatment function testing of platelets and long-term outcome of patients with peripheral arterial disease undergoing transluminal angioplasty. Eur J Vasc Endovasc Surg. 201 I; 42(6): 809-816, doi: 10.1016/j. ejvs.2011.08.014, indexed in Pubmed: 21917489.

40. Snoep JD, Hovens MMC, Eikenboom JCJ, et al. Association of laboratory-defined aspirin resistance with a higher risk of recurrent cardiovascular events: a systematic review and meta-analysis. Arch Intern Med. 2007; 167(15): 1593-1599, doi: 10.1001/ archinte.167.15.1593, indexed in Pubmed: 1769868I.

4I. Ichiki K, Ikeda H, Haramaki N, et al. Long-term smoking impairs platelet-derived nitric oxide release. Circulation. 1996; 94(I2): 3109-3 | |4, doi: 10.1 |61/01.cir.94. 12.3 109, indexed in Pubmed: 8989117.

42. Blache D. Involvement of hydrogen and lipid peroxides in acute tobacco smoking-induced platelet hyperactivity. Am J Physiol. 1995; 268(2 Pt 2): H679-H685, doi: 10.1152/ ajpheart. 1995.268.2.H679, indexed in Pubmed: 7864194.

43. Bhatt DL. What makes platelets angry: diabetes, fibrinogen, obesity, and impaired response to antiplatelet therapy? J Am Coll Cardiol. 2008: 1060-1061.

44. Angiolillo DJ, Suryadevara S. Aspirin and clopidogrel: efficacy and resistance in diabetes mellitus. Best Pract Res Clin Endocrinol Metab. 2009; 23(3): 375-388, doi: 10.1016/j.beem.2008.12.001, indexed in Pubmed: 19520310.

45. Habizal NH, Abdul Ha, Bhaskar S, et al. Prevalence of aspirin resistance in diabetic patients and its associated factors. Malays J Med Sci. 2015;22(I):50-7. Epub 2015/04/22. PubMed PMID: 25892950; PubMed Central PMCID: PMCPMC4390774.

46. Homoródi N, Kovács EG, Leé $\mathrm{S}$, et al. The lack of aspirin resistance in patients with coronary artery disease. J Transl Med. 2016; 14: 74, doi: 10.1 186/s 12967-016-0827-7, indexed in Pubmed: 26980433.
47. Matsagas M, Jagroop IA, Geroulakos G, et al. The effect of a loading dose $(300 \mathrm{mg})$ of clopidogrel on platelet function in patients with peripheral arterial disease. Clin Appl Thromb Hemost. 2003; 9(2): I I5-120, doi: I0.1 I 77// 07602960300900204, indexed in Pubmed: $128 \mid 2379$.

48. Matetzky S, Shenkman B, Guetta V, et al. Clopidogrel resistance is associated with increased risk of recurrent atherothrombotic events in patients with acute myocardial infarction. Circulation. 2004; 109(25): 317I-3175, doi: 10.116I/0I. CIR.0000। 30846.46168.03, indexed in Pubmed: 15184279.

49. Kuliczkowski W, Zembala M, Polonski L, et al. Monitoring of antiplatelet drug effects - fashion or necessity? Kardiol Pol. 2008; 66(I): 119-124.

50. Frere C, Quilici J, Morange PE, et al. High post-treatment platelet reactivity is associated with a high incidence of myonecrosis after stenting for non-ST elevation acute coronary syndromes. Thromb Haemost. 2017; 97(02): 282-287, doi: 10.1160/th0607-0362.

5I. Choi JL, Li S, Han JY. Platelet function tests: a review of progresses in clinical application. Biomed Res Int. 2014; 2014: 456569, doi: 10.1 155/2014/456569, indexed in Pubmed: 24895576.

52. Leytin V, Mody M, Semple JW, et al. Quantification of platelet activation status by analyzing P-selectin expression. Biochem Biophys Res Commun. 2000; 273(2): 565-570, doi: 10.1006/ bbrc.2000.2977, indexed in Pubmed: 10873646.

53. McKenzie ME, Malinin Al, Bell CR, et al. Aspirin inhibits surface glycoprotein Ilb/llla, P-selectin, CD63, and CDI07a receptor expression on human platelets. Blood Coagul Fibrinolysis. 2003; 14(3): 249-253, doi: 10.1097/01.mbc.0000046|82.72384.ab, indexed in Pubmed: 12695747.

54. Silverstein RL, Febbraio M. Identification of lysosome-associated membrane protein-2 as an activation-dependent platelet surface glycoprotein. Blood. 1992; 80(6): 1470-1475, doi: 10.1182/ blood.v80.6. 1470.bloodjournal806 | 470 .

55. Valdes V, Nardi MA, Elbaum L, et al. Reproducibility over time and effect of low-dose aspirin on soluble P-selectin and soluble CD40 ligand. J Thromb Thrombolysis. 2015; 40(I): 83-87, doi: 10.1007/s | |239-0I5-I |79-5, indexed in Pubmed: 25648873.

56. Serebruany VL, Malinin Al, Hanley DF. Magnitude and time course of platelet inhibition with extended release dipyridamole with or without aspirin in healthy Japanese volunteers. The AGgrenox versus Aspirin Therapy Evaluation (AGATE-Japan). Thromb Haemost. 2008; 99(I): I16-120, doi: 10.1160/TH0709-0563, indexed in Pubmed: $18217 \mid 42$.

57. Saunders J, Nambi V, Kimball KT, et al. ELIMIT Investigators. Variability and persistence of aspirin response in lower extremity peripheral arterial disease patients. J Vasc Surg. 20I I; 53(3): 668-675, doi: I0.1016/j.jvs.2010.08.029, indexed in Pubmed: 21227624. 

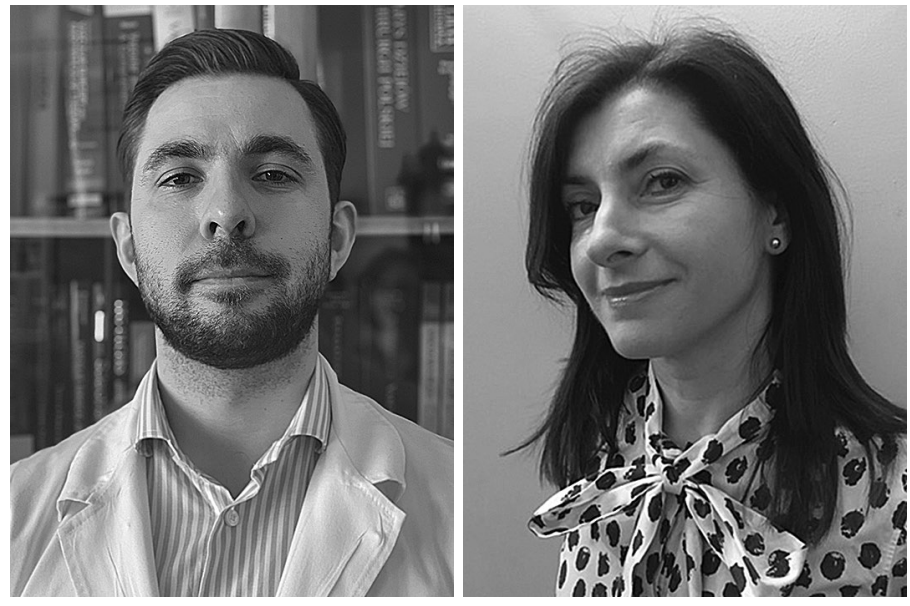

Praca pt.: „Ocena funkcji płytek krwi oraz odporności na aspirynę i klopidogrel u pacjentów z chorobą tętnic obwodowych poddawanych leczeniu wewnątrznaczyniowemu", którą w wersji angielskiej zamieszczono w niniejszym numerze „Acta Angiologica” zdobyła pierwszą nagrodę im. Prof. R. Węgłowskiego. Redakcja serdecznie gratuluje Autorom.

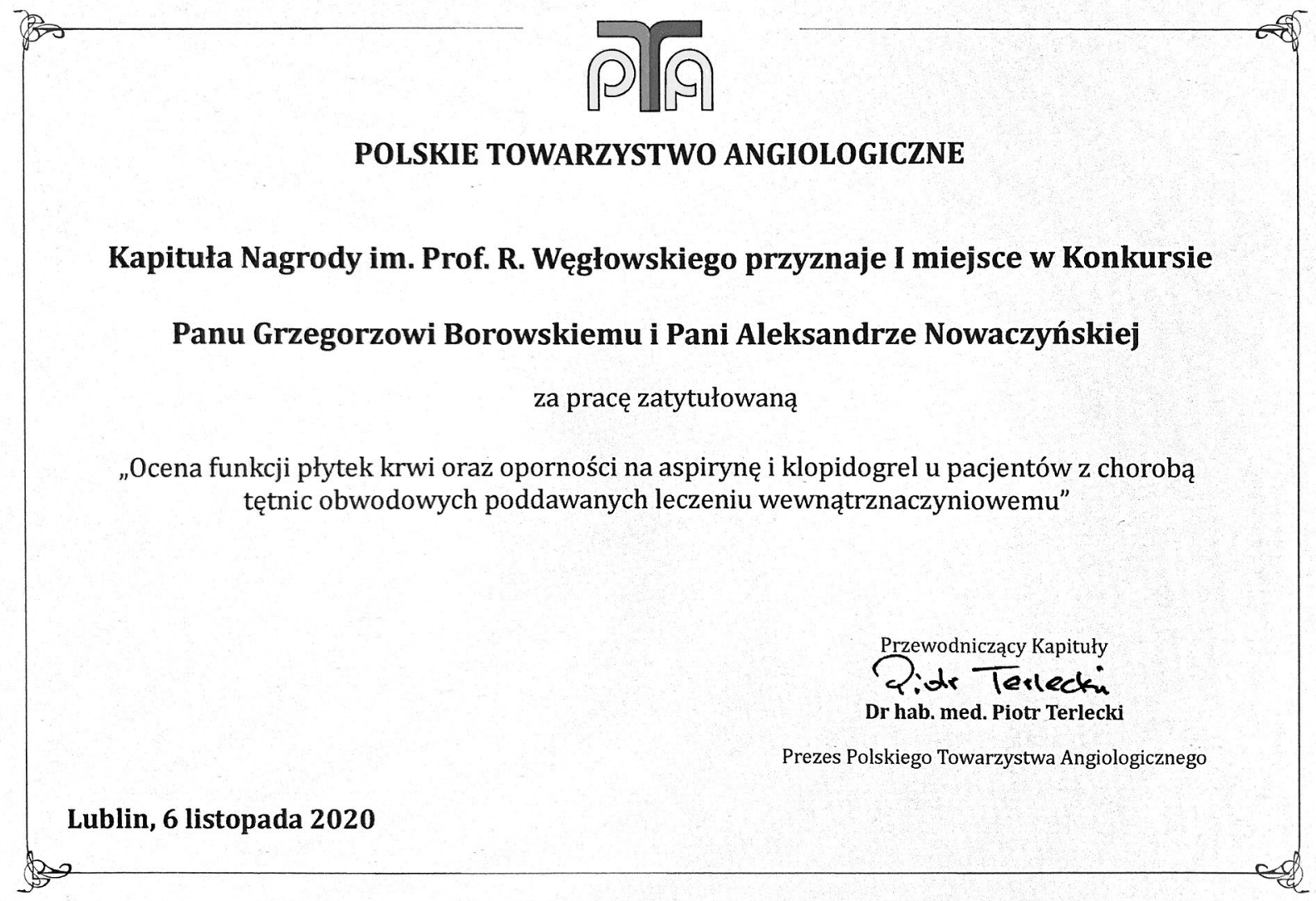

